\title{
Acquisition of Lexical Morphology in Simple Partial Epilepsy
}

\author{
Sébastien Dubé,* Marie-Thérèse Le Normand, $†$ and Henri Cohen $\neq$ \\ *Laboratory of Experimental Psycholinguistics, Université de Genève, Geneva, Switzerland; †Child \\ Neuropsychology Laboratory, Hôpital de la Salpêtrière, Paris, France; and $\ddagger$ Cognitive \\ Neuroscience Center, University of Quebec at Montreal, Montreal, Quebec, Canada
}

Published online April 2, 2001

\begin{abstract}
In the study of language acquisition following early brain damage, results have been divergent. On one hand, some studies claim that language eventually resumes to normal, whereas, on the other hand, studies show lasting deficits throughout development. Discrepancies in the results could arise from different etiologies and tests used. This study attempts to determine the extent to which the development of verb production is affected in later development in children who had simple partial epilepsy (SPE). Measures of diversity and fluency of three verb types, namely main verbs, auxiliary and copula verbs, and nonfinite verbs were used on three children diagnosed as SPE and compared to control groups. Our main results show a limited production of auxiliary verbs. Further analysis of their productions suggest a telegraphic style of speech, as reflected by a superior production of nonfinite verb type compared with normal children. These findings are interpreted as reflecting long-lasting consequences of early brain damage with respect to language development. @ 2001 Academic Press
\end{abstract}

\section{INTRODUCTION}

Early brain damage has often been presumed to be of no lasting consequence for the acquisition of complex cognitive functions or, at most, to have a minimal impact on later stages of development. On the one hand, studies of children with early brain damage have generally shown that language development may appear to proceed normally (e.g., Feldman et al., 1992), suggesting that there are alternate ways to acquire adequate linguistic abilities. For example, Nass (1997) found that toddlers with congenital lesions to either hemisphere show only mild to moderate delays in their acquisition of language.

On the other hand, a growing number of studies have found detectable deficits affecting linguistic abilities (e.g., Dennis \& Kohn, 1975; Dennis \& Whitaker, 1976). Reilly, Bates, and Marchman (1998), for instance, have found that although expressive deficits associated with left temporal damage subsided after 5 years of age, older brain-injured children (between 6 and 9 years of age) performed, in general, significantly below normal controls with regard to syntactic diversity, suggesting that there may be a lasting price when language development follows an alternate route (Martins, 1997).

This research was supported by grants from INSERM, France and SSHRC, Ottawa.

Address correspondence and reprint requests to Henri Cohen, Laboratoire de neuroscience de la cognition, P.O. Box 8888, “Centre-Ville”' Station, Montreal, Quebec, H3C 3P8 Canada. E-mail: cohen.henri@uqam.ca. 
Differences in etiology and in the linguistic tests and assessments conducted may explain these divergent results. It is often the case that children of varying ages with unilateral, bilateral, unifocal, and multifocal lesions are grouped together in order to investigate the relationship between site of lesion and development of adequate language. Also, most studies of language development are cross sectional and do not capture the sequence of stages in atypical populations of children.

The study of epileptic disorders may help with the investigation of linguistic development following brain damage. However, it has been shown that epileptic seizures generally lead to varying outcomes in linguistic performance due to their widespread foci and long-lasting effects. At one extreme, Landau-Kleffner syndrome (Landau \& Kleffner, 1957), a special outcome of partial epilepsy, is characterized by an abrupt childhood aphasia with progressive and often incomplete recovery of linguistic faculties (Deonna, 1996). One conrasting form of partial epilepsy is simple partial epilepsy (SPE), characterized by mild, localized, and transient epileptic foci (Deonna, 1996; Dulac et al., 1983; Morrel, 1995). Partial epilepsy appears early in life, and it could well have an impact on normal growth. From this perspective, it would be of primary interest to take advantage of the mild nature of partial epilepsy, which does not result in the serious deficits of Landau-Kleffner syndrome.

In this longitudinal study, we attempt to determine whether one aspect of language acquisition - verb production-is affected in children with SPE. Verbs are central to more elaborate linguistic abilities and are considered good predictors of other aspects of the child's early grammatical competence (Bates, Bretherton, \& Snyder, 1988). Brown (1973a) has shown that the order of acquisition of 14 morphemes of the English language is remarkably constant in children. Within that set of morphemes, some were related to the acquisition of verbs. Although Brown (1973b) acknowledged that this result was specific to English, the stable ordering of morphemes has been shown to have cross-linguistic validity (Slobin, 1971). By 3 years of age, proper verb usage is still under development (Tomasello, 1992). In this study, we consider the development of verb production in SPE children at 38, 45, and 55 months of age. Measures of diversity and fluency were collected in order to adequately evaluate verb production.

\section{METHOD}

\section{Subjects}

Three right-handed children (cases LA, BB, and $\mathrm{PH}$ ) from the department of pediatrics at the Necker Children's and La Salpêtrière Hospitals were selected on the basis of a diagnosis of perinatal SPE to the left frontal lobe. Diagnostic confirmation and localization of an epileptic focus in the left frontal lobe were done by Dr. Jean Aicardi and his team. Drug therapy was prescribed for a maximum of 2 years and, by age 3, all three SPE children were off anticonvulsive medication. Two control groups ( $N$ $=51$, each) also participated in the study (cf. Le Normand \& Cohen, 1999). All subjects were shown to have normal hearing, based on an audiometric examination, no psychopathological disorders, and a development quotient above 90, as evbaluated with the Brunet-Lézine scale (1965). All children had French as their mother tongue.

\section{Task and Language Procedure}

The spontaneous linguistic productions used in the study were video- and audiotaped during a 20min standardized free-play session (Le Normand, 1986). The set-up included Fisher-Price toy figurines and replicas of household items. Subjects were tested individually in an interaction with one adult. Transcription, coding, and analysis of verbal interactions were done following the Child Language Data Exchange System (CHILDES; MacWhinney \& Snow, 1985, 1991) convention for automated analysis of language transcripts. Interrater agreement of the transcribed material was over $90 \%$. The young pa- 
TABLE 1

Production of Verbs by Two Groups of Controls

\begin{tabular}{lllll}
\hline $\begin{array}{l}\text { Age } \\
\text { (months) }\end{array}$ & \multicolumn{1}{c}{ Main } & \multicolumn{1}{c}{ Auxiliary } & \multicolumn{1}{c}{ Nonfinite } & Total \\
\hline 42 & $\mathrm{D}=14(36) \pm 7$ & $\mathrm{D}=19(49) \pm 8$ & $\mathrm{D}=6(15) \pm 3$ & $\mathrm{D}=39$ \\
& $\mathrm{~F}=27(29) \pm 17$ & $\mathrm{~F}=38(40) \pm 17$ & $\mathrm{~F}=29(31) \pm 17$ & $\mathrm{~F}=94$ \\
60 & $\mathrm{D}=42(58) \pm 15$ & $\mathrm{D}=22(31) \pm 17$ & $\mathrm{D}=8(11) \pm 7$ & $\mathrm{D}=72$ \\
& $\mathrm{~F}=110(40) \pm 57$ & $\mathrm{~F}=91(33) \pm 57$ & $\mathrm{~F}=73(27) \pm 40$ & $\mathrm{~F}=274$ \\
\hline
\end{tabular}

Note. $\mathrm{D}=$ diversity; $\mathrm{F}=$ fluency. Data are presented as follows: $(N=51)-(\%$ of total production $)$ $\pm \mathrm{SD}$.

tients were tested at 38,45 , and 55 months of age. The data from control children were collected at 42 and 60 months of age.

\section{Measures}

Diversity and fluency measures for verb production were calculated for each subject. Verbs produced were classified into the main, auxiliary, and nonfinite categories as in Le Normand and Cohen (1999). Main verbs include verbs that are conjugated in the simple tenses (e.g., I look, I have an apple, and he ran); auxiliary and copula verbs are the have and be forms used in the perfect tenses, generally reflecting past actions (e.g., I have seen); and nonfinite verbs include infinitive, past participle, and modal verb forms (e.g., I have seen and I'm leaving). "Diversity" refers to the number of different verbs used and "fluency" to the frequency of occurrence of each verb type. Thus, each subject contributed three measures of verb diversity and three measures of verb fluency at each test period. Subjects in the control groups were tested at 42 and 60 months old. The data from the control groups for the same tasks and measures are shown in Table 1.

\section{RESULTS}

The analysis of LA's verb use showed different patterns of acquisition over time for each verb type. An increase in production, both in diversity and fluency, was observed only in the main verb category. Very little change was observed in the other verb categories. However, the fluency of the nonfinite verb type showed a marked decrease. Relative to controls, LA's verb production showed a near total absence of auxiliary verbs and an overrepresentation of nonfinite verbs. Table 2 shows the distribution of LA's verb categories.

BB's verb production was, in general, similar to LA's. Here again, use of auxiliary

TABLE 2

LA's Verb Production (\% of Total Production)

\begin{tabular}{lllll}
\hline $\begin{array}{l}\text { Age } \\
\text { (months) }\end{array}$ & Main & Auxiliary & Nonfinite & Total \\
\hline 38 & $\mathrm{D}=5(33)$ & $\mathrm{D}=1(7)$ & $\mathrm{D}=6(40)$ & $\mathrm{D}=15$ \\
& $\mathrm{~F}=8(28)$ & $\mathrm{F}=1(3)$ & $\mathrm{F}=20(69)$ & $\mathrm{F}=29$ \\
45 & $\mathrm{D}=11(58)$ & $\mathrm{D}=1(6)$ & $\mathrm{D}=6(33)$ & $\mathrm{D}=18$ \\
& $\mathrm{~F}=29(40)$ & $\mathrm{F}=2(5)$ & $\mathrm{F}=7(18)$ & $\mathrm{F}=38$ \\
55 & $\mathrm{D}=10(53)$ & $\mathrm{D}=2(11)$ & $\mathrm{D}=7(37)$ & $\mathrm{D}=19$ \\
& $\mathrm{~F}=26(65)$ & $\mathrm{F}=6(15)$ & $\mathrm{F}=8(20)$ & $\mathrm{F}=40$ \\
\hline
\end{tabular}

Note. $\mathrm{D}=$ diversity; $\mathrm{F}=$ fluency. 
TABLE 3

BB's Verb Production (\% of Total Production)

\begin{tabular}{lllll}
\hline $\begin{array}{l}\text { Age } \\
\text { (months) }\end{array}$ & Main & Auxiliary & Nonfinite & Total \\
\hline 38 & $\mathrm{D}=2(50)$ & $\mathrm{D}=1(25)$ & $\mathrm{D}=1(25)$ & $\mathrm{D}=4$ \\
& $\mathrm{~F}=4(66)$ & $\mathrm{F}=1(17)$ & $\mathrm{F}=1(17)$ & $\mathrm{F}=6$ \\
45 & $\mathrm{D}=10(45)$ & $\mathrm{D}=2(10)$ & $\mathrm{D}=10(45)$ & $\mathrm{D}=22$ \\
& $\mathrm{~F}=28(65)$ & $\mathrm{F}=2(5)$ & $\mathrm{F}=13(30)$ & $\mathrm{F}=43$ \\
55 & $\mathrm{D}=16(55)$ & $\mathrm{D}=1(3)$ & $\mathrm{D}=12(41)$ & $\mathrm{D}=29$ \\
& $\mathrm{~F}=47(71)$ & $\mathrm{F}=2(3)$ & $\mathrm{F}=17(26)$ & $\mathrm{F}=66$ \\
\hline
\end{tabular}

Note. $\mathrm{D}=$ diversity; $\mathrm{F}=$ fluency.

verbs was quite limited. Otherwise, there was a marked increase in both diversity and fluency for the other verb categories. Table 3 shows the changes in BB's production.

Except for nonfinite verbs, the young patient $\mathrm{PH}$ showed a pattern of verb production similar to those of LA and BB. In this case also, use of auxiliary verbs was very limited. Production of nonfinite verbs, however, was normal. Table 4 shows PHs performance on verb production over time.

\section{DISCUSSION}

Verb acquisition was investigated in three children with SPE in an effort to determine the long-term consequences of early and transient brain damage to the left hemisphere. The consistent finding, in every case, of a limited production of auxiliary verbs suggests that these children show impairments, or at least delays, in aspects of their linguistic production, relative to normal controls. In this respect, it would seem that transient early brain damage to the left hemisphere has deleterious consequences on linguistic development in terms of both diversity and fluency.

With respect to diversity, SPE children produced fewer different verbs in the main and auxiliary categories. Their production of different nonfinite verbs, however, is superior to that of control children. With respect to fluency, the data also revealed that the SPE children's performance was poorer than that of controls. It is clear that the linguistic development of these children shows an increase in the verb lexicon over time; however, the rate of acquisition is not as marked as that of the control children over the same period.

This study revealed a specific profile of language developent in SPE children: Acquisition and production of auxiliary verbs is almost absent. Auxiliaries belong

TABLE 4

PH's Verb Production (\% of Total Production)

\begin{tabular}{llllr}
\hline $\begin{array}{l}\text { Age } \\
\text { (months) }\end{array}$ & Main & Auxiliary & Nonfinite & Total \\
\hline 38 & $\mathrm{D}=11(38)$ & $\mathrm{D}=1(3)$ & $\mathrm{D}=17(59)$ & $\mathrm{D}=29$ \\
& $\mathrm{~F}=25(37)$ & $\mathrm{F}=5(7)$ & $\mathrm{F}=37(55)$ & $\mathrm{F}=67$ \\
45 & $\mathrm{D}=10(33)$ & $\mathrm{D}=1(3)$ & $\mathrm{D}=19(63)$ & $\mathrm{D}=30$ \\
& $\mathrm{~F}=13(27)$ & $\mathrm{F}=11(23)$ & $\mathrm{F}=24(50)$ & $\mathrm{F}=48$ \\
55 & $\mathrm{D}=23(51)$ & $\mathrm{D}=1(2)$ & $\mathrm{D}=21(47)$ & $\mathrm{D}=45$ \\
& $\mathrm{~F}=52(68)$ & $\mathrm{F}=2(3)$ & $\mathrm{F}=23(30)$ & $\mathrm{F}=77$ \\
\hline
\end{tabular}

Note. $\mathrm{D}=$ diversity; $\mathrm{F}=$ fluency 
to the class of function words (Stromswold, 1995) and, as such, are necessary to produce more abstract utterances reflecting, for instance, past events. A deficit in the production of auxiliaries probably reflects a more general impairment in the use of function words. Closer examination of the SPE children's transcriptions reveals frequent telegraphic productions, based on the "here and now.' These results are consistent with others showing that younger children with left-hemisphere damage are at risk for developmental linguistic outcomes.

It is not clear whether these children are permanently impaired or only delayed with regard to their linguistic capacity. Locke's (1997) theory of neurolinguistic development suggests an interesting prediction. Locke argued that children normally go through four stages of linguistic development: vocal learning, utterance acquisition, analysis and computation, and, finally, integration and elaboration. Proper learning takes place only if a sufficient amount of information has been acquired in one stage when the subsequent stage begins; otherwise, linguistic acquisition will be delayed. In the case of children with SPE, a persistent impairment of language development may be a consequence of their inability to make adequate use of auxiliaries. It would be interesting to determine whether these children's later stages of linguistic development are still characterized by delays or deficits.

\section{REFERENCES}

Bates, E., Bretherton, I., \& Snyder, L. (1988). From first words to grammar: Individual differences and dissociable mechanisms. Cambridge, UK: Cambridge Univ. Press.

Brown, R. (1973a). A first language: The early stages. Cambridge, MA: Harvard Univ. Press.

Brown, R. (1973b). Development of the first language in the human species. American Psychologist, February, 97-106.

Brunet, O., \& Lézine, I. (1965). Le développement de la première enfrance: Présentation d'une échelle pour l'examen des tous petits. Paris: Presses Universitaires de France.

Dennis, M., \& Kohn, B. (1975). Comprehension of syntax in infantile hemiplegia after cerebral hemidecortication: Left hemisphere superiority. Brain and Language, 2, 474-482.

Dennis, M., \& Whitaker, H. A. (1976). Language acquisition after hemidecortication: Lingustic superiority of the left over the right hemisphere. Brain and Language, 3, 404-433.

Deonna, T. (1996). Troubles du langage et épilepsie. In C. Chevrie \& J. Narbona (Eds.), Le langage de l'enfant: Aspects normal et pathologique (pp. 27-42). Paris: Masson.

Dulac, O., Billard, C., \& Arthuis, M. (1983). Aspects électrocliniques et évolutifs de l'épilepsie dans le syndrome aphasie-épilepsie. Archives Françaises de Pédiatrie, 40, 299-308.

Feldman, H. M., Holland, A. L., Kemp, S. S., \& Jonosky, J. E. (1992). Language development after unilateral brain injury. Brain and Language, 42, 89-102.

Landau, W. M., \& Kleffner, F. R. (1957). Syndrome of acquired aphasia with convulsive disorder in children. Neurology, 7, 523-530.

Le Normand, M-T. (1986). A developmental exploration of language used to accompany symbolic play in young normal children (2-4 yr old). Child Care and Health Development, 12, 121-134.

Le Normand, M.-T., \& Cohen, H. (1999). The delayed emergence of lexical morphology in preterm children: The case or verbs. Journal of Neurolinguistics, 12, 235-246.

Locke, J. L. (1997). A theory of neurolinguistic development. Brain and Language, 58, 265-326.

MacWhinney, B., \& Snow, C. E. (1985). The Child Language Data Exchange System (CHILDES). Journal of Child Language, 12, 271-296.

MacWhinney, B., \& Snow, C. E. (1991). CHILDES manual. Hillsdale, NJ: Erlbaum.

Martins, I. P. (1997). Childhood aphasias. Clinical Neuroscience, 4, 73-77.

Morrel, F. (1995). Electrophysiology of CSWS in Landau-Kleffner syndrome. In A. Beaumanoir, M. Bureau, T. Deonna, L. Mira, \& C. A. Tassinari (Eds.), Continuous spikes and waves during slow sleep, electrical status epilepticus during slow sleep (pp. 77-90). London: John Libbey.

Nass, R. (1997). Language development in children with congenital strokes. Seminars in Pediatric Neurology, 4, 109-116. 
Reilly, J. S., Bates, E. A., \& Marchman, V. A. (1998). Narrative discourse in children with early focal brain injury. Brain and Language, 61, 335-375.

Slobin, D. I. (1971). Developmental psycholinguistics. In W. O. Dingwall (Ed.), A survey of linguistic science. College Park: Linguistics Program, University of Maryland.

Stromswold, K. (1995). The cognitive and neural bases of language acquisition. In M.S. Gazzaniga (Ed.), The cognitive neurosciences (pp. 855-870). Cambridge, MA: MIT Press.

Tomasello, M. (1992). First verbs. Cambridge, UK: Cambridge Univ. Press. 